\title{
Measuring the Digital Economy and Society: A Study on the Application of the Digital Economy and Society Index in the Western Balkans
}

\author{
Zoran Jordanoski \\ United Nations University Operating Unit on \\ Policy-Driven Electronic Governance (UNU-EGOV) \\ jordanoski@unu.edu
}

\author{
Morten Meyerhoff Nielsen \\ United Nations University Operating Unit on \\ Policy-Driven Electronic Governance (UNU-EGOV) \\ meyerhoff@unu.edu
}

\begin{abstract}
Measuring the digital socio-economic transformation is an essential part of good, appropriate, knowledge-based decision making. Multiple national and international indexes measure the various aspects of the digital transformation, such as the telecommunication infrastructure development, digital skills, eGovernment, eCommerce, eBusiness, etc. Focusing on the integration of the indicators that affect the digital economy and society, the European Union (EU) launched the Digital Economy and Society Index (DESI) in 2014 aimed to measure the progress made by the EU Member States in the progress in digital performance and competitiveness. Composed of five dimensions, DESI measures both, the impact of the digital transformation on the Digital Economy and Digital Society.

As the DESI and its indicators are part of the EU Acquis Communautaire, all candidates and potential candidates for EU membership must be prepared to provide complete datasets for measuring the indicators introduced and used by the EU. Currently, all Western Balkan (WB) economies are either candidates or potential candidates for EU membership. With the digital agenda ranked high on the government agendas, this raises the questions of the level of preparedness of the WB economies in providing the complete highquality datasets required to calculate the DESI. Specifically, how is the WB economy data methodologically aligned with the DESI and other relevant EU methodologies (e.g. Survey on ICT usage in households and by individuals, Study on Broadband Coverage in Europe, eGovernment Benchmark Study, etc.)? This paper aims to assess the readiness of each WB economy to provide the complete datasets for the DESI indicators. Key findings are that WB economies are generally ready to provide methodologically align data for the DESI indicators, especially for the indicators that use data from the national databases. Key challenges in the existing domestic methodologies are generally linked to the indicators that are extracted from the Commission ad hoc studies, especially for those where the WB economies (or some of them) are not included.
\end{abstract}

Permission to make digital or hard copies of all or part of this work for personal or classroom use is granted without fee provided that copies are not made or distributed for profit or commercial advantage and that copies bear this notice and the full citation on the first page. Copyrights for components of this work owned by others than ACM must be honored. Abstracting with credit is permitted. To copy otherwise, or republish, to post on servers or to redistribute to lists, requires prior specific permission and/or a fee. Request permissions from permissions@acm.org.

ICEGOV 2021, October 06-08, 2021, Athens, Greece

(C) 2021 Association for Computing Machinery.

ACM ISBN 978-1-4503-9011-8/21/10 . \$ \$15.00

https://doi.org/10.1145/3494193.3494220

\section{CCS CONCEPTS}

- Applied computing - E-government; • General and reference - Measurement;

\section{KEYWORDS}

Measurement, Digital Economy, Digital Society, DESI Index, Western Balkan

\section{ACM Reference Format:}

Zoran Jordanoski and Morten Meyerhoff Nielsen. 2021. Measuring the Digital Economy and Society: A Study on the Application of the Digital Economy and Society Index in the Western Balkans. In 14th International Conference on Theory and Practice of Electronic Governance (ICEGOV 2021), October 06-08, 2021, Athens, Greece. ACM, New York, NY, USA, 8 pages. https://doi.org/10.1145/3494193.3494220

\section{INTRODUCTION}

Information and Communication Technology (ICT) has been on the European Union (EU) agenda since 1994 following the adoption of the Bangemann report at the European Council in Corfu, Greece [1], [2]. Aligned with global trends, the focus has been changed over the years, moving from establishing e-Europe initiative in 1999 [2] to enabling smart sustainable and inclusive growth, including the establishment of a single digital market in 2010-2020 agenda [3], and use of new technologies for innovation, inclusion, accountability and sustainability [4]. The measurement of the digital transformation was also considered an essential part of the digital agenda. Over time, various indicators have been applied by the European Commission (EC) to measure the strategical performance of the telecommunication sector, internet usage by households, individuals and enterprises, eCommerce, eGovernment, eBusiness, eHealth, digital skills, security and privacy, etc. [5] In order to improve the measurement of policy performance and contribute to sound, knowledge-based decision making, the focus have shifted towards measuring the digital economy and society. As a result of the progress and evolving strategic focus of the digital transformation in Europe, the EC realigned its existing measurement matric and indictors by introducing the Digital Economy and Society Index (DESI) in 2014 [6]-[8]. As a composite index, DESI measures five key areas: connectivity, human capital, use of internet by individuals, integration of digital technologies by the business sector and digital public services [9], [10]. The index allows individual and general performance assessment, distinguish the areas where performance could be improved, monitor the progress over time and comparative analysis of different EU member states or clusters of states [7], [9]. 
The EU Digital agenda and its regulations become mandatory for all candidate and potential candidate countries for EU membership. The term "Western Balkan" (WB) was first coined during the conclusion of the EU-Western Balkan Summit Declaration in June 2003 [11]. The Summit confirmed the prospects of potential future membership for all WB countries once the European standards and criteria are met (i.e. the Acquis Communautaire). It is important to note that the WB group's economies have changed since 2003 as individual countries have become members of the EU. Initially including Albania, Bosnia and Herzegovina, Croatia, Macedonia (the former Yugoslav Republic of Macedonia, now North Macedonia), Serbia and Montenegro (federation). Croatia (in 2013) become a member of the EU, Montenegro peacefully seceded for independence in 2006 [12] while Kosovo* unilaterally declared its independence from Serbia in 2008 [13]. Today the composition of the WB region (WB economies ${ }^{1}$ ) now includes Albania (AL), Bosnia and Herzegovina (BA), Kosovo* (XK), Montenegro (ME), North Macedonia (MK) and Serbia (RS). As of May 2021, Albania, Montenegro, North Macedonia and Serbia are formally candidates, while Bosnia and Herzegovina and Kosovo* are still potential candidates for EU membership [14]. As candidates or potential candidates for EU membership, the use of DESI indicators to measure the progress made by the Western Balkan (WB) economies is a formal requirement of the Acquis Communautaire.

The paper is structured as follows: Section 2 review the literature on the research subject. The methodology and how the study was conducted is presented in Section 3. The study results and discussion are presented in Section 4, while the conclusions and future work are included in Section 5.

\section{LITERATURE REVIEW}

The rapid pace of technological developments and globalization continues to change the socio-economic contexts of both Europe and the WB economies [7]. Globally, ICT has become a strategic tool and enabler of both, public and private sector innovation and growth of productivity [15], [16]. The digital transformation brings about both socio-economic opportunities and challenges [17], [18]

ICT, and technology in general, have long been a topic of both policy and academic study. Computer science and information systems management have long studied the implication of technology on organisations [19][20], but with the emergence of the electronic government (eGovernment) term in 1993, the 1990s and early 2000 s saw an increasing focus on the public sector as an increasingly separate field of study [21], [22]. The roll-out and popularity of the Internet and the acceleration of ICT enabled innovation and digital transformation have only added to this.

Nicholas Negroponte was among the first to analyse the idea of the digital economy and the impact of the digital revolution in people social life, work, business, commerce, entertainment, etc. [23]. Also, Don Tapscott using the term 'Digital Economy', provided an overview of how the Internet will change the way the business operates [24]. Defining it later, Mesenbourg distinguished three

\footnotetext{
${ }^{1}$ The term economies instead of countries is used in the paper since not all WB economies are officially members of the United Nations and recognized by the EU Member States. The use of the name of Kosovo* is without prejudice to positions on its status, and is in line with United Nations Security Council Resolution 1244 and the International Court of Justice Opinion on the Kosovo* Declaration of Independence.
}

main components of the 'Digital Economy', such as E-business infrastructure (hardware, software, telecom, networks, human capital, etc.), E-business (how business is conducted, any process that an organization conducts over computer-mediated networks), and E-commerce (transfer of goods, for example when a book is sold online) [25]. Raisinghani also identifies four pillars that together establish the digital economy: technical changes influenced by the ICT development, social changes caused by the increased use of the ICT; microeconomics level of changes; and, macroeconomic level of changes [26].

The potential role of ICT and the digital economy in job and wealth creation has led to a strategic focus on the transition to first the information and knowledge society and later the digital economy. It also brought changes in peoples lives and affected the overall communication, social interaction, behaviours and quality of life [27]. Digital innovations are changing the way our society and economy operates. It provides new tools that empower individuals, their ability and skills to actively participate in policy creation and decision-making [28]. Similarly, technology-enabled innovation in society has the potential to bring about a better quality of life, financial and environmental sustainability in multiple domains, such as the economy and social inclusion, social equity, open and transparent government and service delivery [29], [30].

The question of how to monitor and measure the envisioned ICT enabled transition has been a key question for some time. Since the digital changes have such a significant impact on all aspects of the economy and society, the collection of the necessary high-quality data for the measurement of this change is essential [31]. The objective of monitoring the digital transformation progress is to inform public decision-making as part of sustainable governance [32]. To be of value for decision-makers, any statistical indicator must nonetheless be valid, practical, quantifiable, directional, actionable and even financial [33]-[35]. Haltiwanger and Jarmin distinguish five types of data necessary for measuring the digital economy. These data include Information Technology Infrastructure, eCommerce, Firm and Industry Structure, Demographic and Worker Characteristics, and Price Behavior [31]. This also bring do need for measurement of the ICT use by individuals, companies, the level of development of the ICT infrastructure, digital skills and eGovernment, which led to the establishment of more than twenty indexes relating to the quantitative measurement of the digital economy and the use of ICT [8], [36]. Globally multiple benchmarks directly or indirectly measuring various aspects of ICT use in society, the private and public sector have been launched. Prominent examples of research reports based on international benchmarks to measure progress towards various aspects of a digital society include the World Economic Forum's Global Information Technology Report [37], [38] including its Network Readiness and Global Competitiveness Indexes, the Economist Intelligence Unit's The Inclusive Internet Index [39], the Partnership on Measuring ICT for Development coordinated and funded by the International Telecommunications (ITU) [40], the United Nations Department for Economic and Social Affairs (UNDESA) E-Government Development Index (EGDI) [41], the Waseda University's Digital Governance Ranking [42], or the Web Foundation's Alliance for Affordable Internet annual Affordability Drivers Index [43]. In the EU context, several indicators were introduced and used to measure the progress in the telecommunication sector, 
internet usage by individuals and enterprises, eCommerce, eGovernment, eBusiness, eHealth, digital skills, security and privacy, etc. [5]. It is in this light the EC and the EU Member States agreed on the Digital Economy and Society Index (DESI) in 2014, to measure the progress in the digital performance and competitiveness made by the EU Member States (currently 27). Recognising the potential of DESI, the EC piloted the I-DESI (International DESI) in 2018 in order to measure the progress of the 17 EU Member States and 18 non-EU Member States. The I-DESI differs from the European DESI in several indicators but allows for cross-country comparisons.

Since its establishment in 2014, DESI has been the subject of academic research aiming. Research to date largely tried to understand how the digital transformation affects the economy and society and what progress is made by the EU Member States. Specifically, the DESI has been used by academics to understand and compare the progress made by the groups or the individual EU Member States across different areas of the digital transformation, but also in relation to the government services, the economic, social, or cultural aspects. One of the main benefits of DESI is the possibility of monitoring the progress made by individual countries over time in relation to both EU and national strategies and activities [44]-[47]. Regional and local DESI indicators are also providing a development framework [48]. Similarly, DESI and its usability by researchers are for cross-country analysis and monitoring the progress made over time [49]-[52].

DESI in general, or any of its five dimensions, are used by governments, practitioners and academia to measure the individual or regional progress for specific areas. For instance, the Connectivity and the Human Capital dimensions were determined as 'independent variables', which determines the success of the other three dimensions (Use of Internet, Integration of Digital Technology, and Digital Public Services) [10]. DESI was also used in the context of entrepreneurship to understand the correlation between digitalization and profitability [53], the possibilities of smart business [54] and positive effects on cross-border business [51]. Also, DESI helped researchers to analyse the human capital elements in the context of adults online learning [49]. DESI was also useful to monitor the development of eGovernment [46], [47], [50]. The uniqueness of DESI is that it encompasses five different but interconnected areas that are already measured by other entities worldwide. For example, the ITU already measures the connectivity dimension (Telecommunication Infrastructure Index) and the use of Internet by households, individuals and enterprises. UNESCO, in turn, measures the human capital and digital skills dimension (Human Capital Index). Lastly, the Digital Service Dimension is measured by UNDESA through the EGDI [55][16]. The DESI thus combine a number of elements seen in other global benchmarks but tend to do this in greater detail for the indicators chosen, not lease related to skills (e.g. specific online and IT related skills and tasks), use of technology (e.g. specific type of online service offers and activities) for citizen and business-related activities. DESI also segment data to a greater detail including by gender, age groups, educational and income levels, although it varies depending on the actual indicator. Lastly, in the context of the EU and wider European context, the DESI is the ECs tool to monitor performance of Member States in relation to strategic objectives, as well as for individual governments to measure and benchmark national performance. This includes the progress by potential candidate countries, such as the WB economies, making DESI compliant data capture a national policy priority. As some of the data collected for the DESI is also provided to other benchmarks like those of the ITU (e.g. internet and telecommunication infrastructure) and UNESCO (e.g. on educational attainment levels) the importance of the capabilities of WB economies to collect data according to specific methodologies are particularly important.

To assist the WB economies in measuring the progress, the EC is carrying out a study to monitor the progress made towards compliance with the EU rules and regulations. The three Study Reports noted that "complete datasets from the region for all DESI dimensions are currently missing, and therefore integration with the EU DESI can only take place progressively as the relevant WB authorities are able to provide the full datasets, in accordance with the EU acquis on statistics, where applicable" [56]-[58]. As all WB economies are candidates or potential candidates for EU membership, the research questions of this research are: How prepared are the WB economies to provide full datasets for each DESI indicator? How are these data methodologically aligned with the DESI and other relevant methodologies (i.e. methodologies for measurement of each indicator individually)?

\section{METHODOLOGY}

To explore the research questions, an explanatory, qualitative, multiple-case comparative study methodology is applied [59]-[61]. Through a within-case analysis, the objective is to identify the readiness of each economy to provide data for all DESI 2020 indicators, thereby enabling a cross-case comparison.

Primary sources for the article include the relevant documents [62], such as EU and domestic WB policies, regulations, guidelines, strategies, reports and other documents relevant for the Information and Communications Technology (ICT) sector in general, and more specifically, the acquis on statistics and application and measurement of DESI indicators. The objective was to identify the authorities responsible for data collection for all DESI 2020 indicators, and the existence of domestic regulations and methodologies in WB economies. Data, including metadata for each dataset, was obtained from the official Eurostat database [63], databases of the National Statistical Institutes (NSIs) ${ }^{2}$ [64]-[69], and the periodical (monthly/quarterly/annual) reports of the National Regulatory Authorities (NRAs) of the six economies ${ }^{3}$ [70]-[75]. The aim was two-fold. First, to map the available data for all six economies, and second, to review the domestic methodologies and to provide qualitative analysis of their alignment with the DESI 2020 and other relevant EU methodologies such as the Survey on ICT usage in households and by individuals, Survey on ICT Usage in enterprises, Study on Broadband Coverage in Europe, Study on Mobile and

\footnotetext{
${ }^{2}$ NSIs: INSTAT - Institute of Statistics (AL); BHAS - Agency for Statistics of Bosnia and Herzegovina (BA); KAS - Kosovo* Agency of Statistics (XK); MONSTAT - Statistical Office of Montenegro (ME); SSO - State Statistical Office (MK); and SORS - Statistical Office of the Republic of Serbia (RS).

${ }^{3}$ NRAs: AKEP - Agency for Electronic Communications and Post (AL); RAK - Communications Regulatory Agency (BA); ARKEP - Regulatory Authority of Electronic and Postal Communications (XK); Agency for Electronic Communications and Postal Services (ME); Agency for Electronic Communications (MK); Broadband Competence Office (MK); and, RATEL - Republic Agency for Electronic Communications and Postal Service RRS).
} 
Table 1: Questionnaire design (Source: Authors, 2021)

\begin{tabular}{|c|c|c|c|c|}
\hline Indicator & $\begin{array}{l}\text { Is your institution } \\
\text { responsible for data } \\
\text { collection for this } \\
\text { indicator }\end{array}$ & $\begin{array}{l}\text { Is your institution } \\
\text { collect data for this } \\
\text { indicator }\end{array}$ & $\begin{array}{l}\text { What is the frequency } \\
\text { of data collection }\end{array}$ & $\begin{array}{l}\text { Is your methodology } \\
\text { aligned with DESI } \\
\text { Methodology }\end{array}$ \\
\hline $\begin{array}{l}\text { DESI Indicator } 1 \\
\text { DESI Indicator } 2\end{array}$ & Yes/No/Unsure & Yes/No/Unsure & Yes/No/Unsure & $\begin{array}{l}\text { Annual/Semi-annual/ } \\
\text { Quarterly/Monthly/ Other }\end{array}$ \\
\hline $\begin{array}{l}\ldots \\
\text { DESI Indicator } 37\end{array}$ & & & & \\
\hline
\end{tabular}

Table 2: Assessment criteria for each DESI 2020 indicator (Source: Authors, 2021)

\begin{tabular}{ll}
\hline $\begin{array}{l}\text { Data available and fully aligned with DESI } \\
\text { Methodology }\end{array}$ & $\begin{array}{l}\text { Data available but not fully aligned with } \\
\text { DESI Methodology }\end{array}$ \\
\hline \hline
\end{tabular}

Fixed Broadband Prices in Europe, EU-Labour Force Survey (EULFS), UNESCO OECD Eurostat (UOE) joint data collection on education, eGovernment Benchmark Study and Open Data Maturity Study.

To verify the findings and to enrich the research, a standardized online questionnaire with close-ended questions [76], [77] was distributed to 18 institutions (three per economy). The option "unsure" was added since possibilities of overlapping mandates or gaps in the existing domestic regulations, or methodological misalignments were possible and expected. The format of the questionnaire with the possible answers is presented in Table 1

Seventeen of the 18 invited institutions replied positively and accepted participation in the Study. All of them returned the questionnaire filled according to the provided instructions.

As a follow-up, 16 semi-structured interviews were conducted (virtually) with individual representatives from the participating institutions [62], [78]. The aim was to complement the questionnaire by further exploring the domestic regulations and methodologies, their alignment with the EU acquis and methodologies, as well as any existing institutional challenges. Special focus was given to ascertain the level of awareness of the institutions of the importance of the DESI, the institutional readiness and capacities to participate in the data collection process for all indicators, and any other challenges which the institutions are facing in this respect.

Based on the findings, the economy and regional assessments were made. A three-level assessment methodology was implemented to assess the readiness of each economy to provide data for each DESI 2020 indicator as defined in Table 2

Due to data availability, the 2020 edition of the WB DESI was calculated based on the data for 2019 (for the annual indicators) and 2018 (for the bi-annual indicators). The evaluation was made based on the availability of data for the same years (i.e. 2018 and 2019). Where available, an analysis of 2020 data was included to align with the timeliness of data collection and reporting. The aim was first to determine the level of readiness for each economy for each indicator to provide methodologically aligned data, and second, to evaluate the level of readiness of each economy.
When assessing the data availability for each indicator, the black colour is assigned to all indicators for which data is available and fully aligned with DESI 2020 Methodology and/or other relevant EU methodologies. This data is useful for DESI and can be used to compare the performance of the assessed economy with its WB peers and EU Member States. The colour grey is assigned to all indicators for which some data is available, but there is a degree of methodological misalignments with DESI 2020 Methodology and/or other relevant EU methodologies was identified. The methodologies applied for the data collection associated with these indicators need to be revised in order to be fully aligned with DESI Methodology and/or other EU methodologies. Lastly, the white colour is assigned to all indicators for which data is not available.

To standardise the assessment of individual national and organisational methodologies, the compliance with the EU methodologies is categorised into a high level of compliance (the domestic methodology is completely aligned with the relevant EU methodology); significant level of compliance (the domestic methodology is aligned with the relevant EU methodology, but some minor methodological misalignment exists) and low level of compliance (the domestic methodology is not alleged with the relevant EU methodology).

The final assessment evaluates the readiness of each of the WB economies to provide the methodologically aligned data for all DESI 2020 indicators. The readiness assessment was made based on the scale based on the data available and fully aligned with DESI 2020 Methodology:

- Highly prepared: $76-100 \%$.

- Moderately prepared: $51-75 \%$ of the indicators.

- Some level of preparation: $26-50 \%$ of the indicators.

- Early-stage of preparation: 0-25\% of the indicators.

\section{RESULTS OF THE STUDY AND DISCUSSION}

Synthesising the analysis of relevant documents, the questionnaire and interviews (per economy), how prepared are the WB economies to provide full datasets for each DESI indicator? How are these data methodologically aligned with the DESI and other relevant methodologies? The short answer is that $\mathrm{WB}$ as a region is highly 


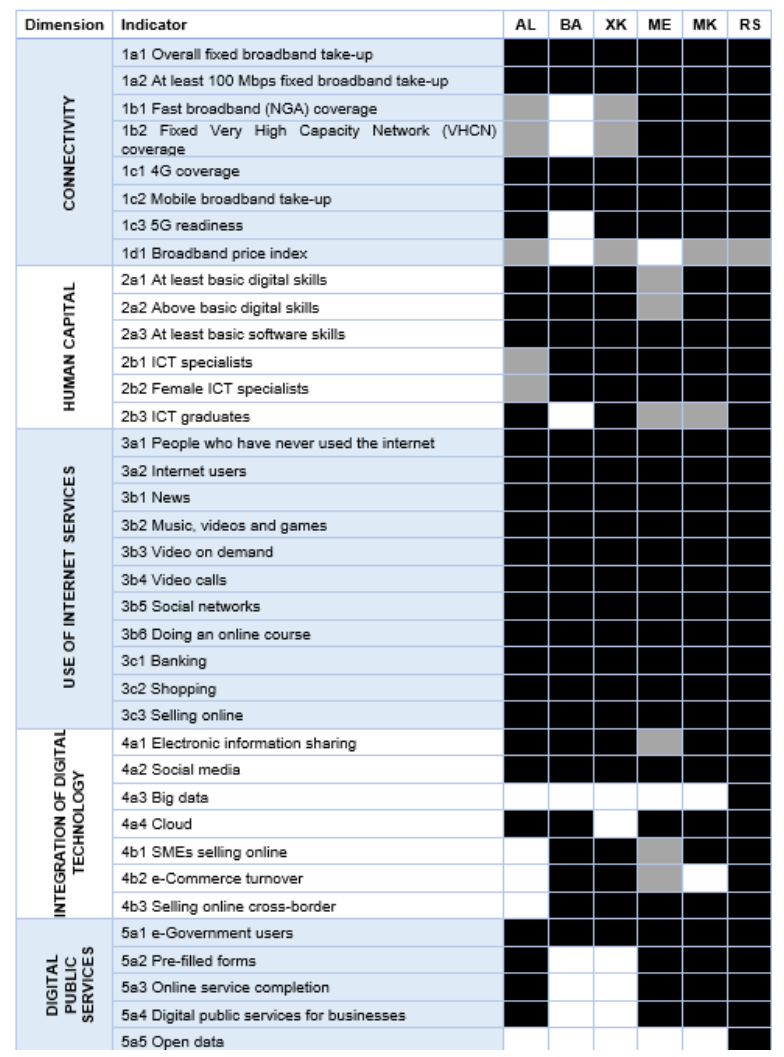

Figure 1: Data available per DESI indicators and its alignments with DESI 2020 Methodology (Source: Authors, 2021)

prepared in terms of ensuring reliable and methodologically aligned data for the calculation of DESI. Currently, WB economies can provide data for $80 \%$ of all DESI 2020 indicators. Data for $8 \%$ of DESI 2020 indicators is available but require further methodological alignments. Unfortunately, data for $12 \%$ of the indicators are still missing.

In terms of economy readiness, Serbia, North Macedonia, Montenegro and Kosovo* are highly prepared, while Albania and Bosnia and Herzegovina are moderately prepared. Currently, Serbia is able to provide data for all 37 DESI 2020 indicators, followed by Montenegro and North Macedonia (34 indicators), Albania (32 indicators),

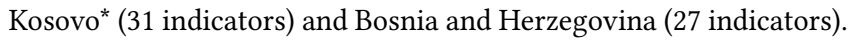
In terms of the alignment with DESI 2020 Methodology, Serbia is also a leader among the WB economies been able to provide methodologically aligned data for 36 indicators of 37 DESI indicators followed by North Macedonia (32 indicators), Montenegro and Kosovo* (28 indicators), Albania and Bosnia and Herzegovina (27 indicators) as shown in Figure 1

The analysis found that all six WB economies have a solid foundation for monitoring the DESI domestically. Most of the relevant DESI indicators are available, with NSIs being responsible for their collection. All NSIs have a high degree of compliance with Eurostat surveys on surveys on ICT usage in households and by individuals and ICT usage in enterprises.
Currently, the biggest challenge remains with the DESI indicators that use data from the Commission ad hoc studies. A significant number of indicators derived from these ad hoc studies are in the Connectivity (five of eight indicators) and Digital public services (four of five indicators) dimensions. Although practice in the EU Member States shows that data for these indicators are not collected domestically, the practice from WBs demonstrates that for some of these indicators, a domestic data collection and calculation is possible in the context of DESI. Namely, the indicators that derive from the Study on Broadband Coverage in Europe (BCE Study) and the 5G Observatory can be calculated domestically, as shown in Montenegro, North Macedonia and Serbia. As all NRAs are already collecting data on the broadband coverage, calculation of the score is possible if the correct methodology is available in advance and NRAs have a reasonable time for internal preparation.

However, a number of the indicators derived from the Study on Mobile and Fixed Broadband Prices in Europe, eGovernment Benchmark Report and Open Data Maturity Report require significant resources, skills and knowledge. Domestic data collection and calculations by each of the WB economies is not feasible due to their complexity, specific methodological requirements, and tools for collection (i.e. mystery shopper).

\subsection{Connectivity dimension}

Data collection for the Connectivity dimension is divided among the NSIs (one indicator) and the NRAs (seven indicators). The analysis finds, the NSIs are responsible for data collection of one indicator (1a1), which derives from the ICT usage in households and by individuals survey. As all NSIs achieved high compliance, data for this indicator is available for all WB economies on Eurostat. With respect to the NRAs, the awareness is high of the importance of monitoring in the Connectivity dimension indicators and as all of them are in a process for full alignment of their methodologies with the Digital Agenda scoreboard key indicators, especially for the Broadband take-up and coverage, Broadband speeds and prices and Mobile market. In that regard, no gaps were found in terms of two Connectivity indicators (1a2 and $1 \mathrm{c} 2)$ as the data is collected and provided by the NRAs.

Challenges and gaps were detected for five indicators as all of them use data from Commission ad hoc studies. Three indicators (1b1, 1b2 and 1c1) use data from the BCE Study, one indicator (1c3) from the European $5 \mathrm{G}$ Observatory, and one indicator (1d1) from the Study on Mobile and Fixed Broadband Prices. Unfortunately, none of the WB economies is included in these studies. That said, the Study finds that the NRAs for most of these indicators collects the relevant data from the telecom operators and are therefore able to calculate the score applying the same methodologies used in the Commission ad hoc studies. The examples of Serbia (RATEL) and North Macedonia (joint efforts of AEC and BCO) shows that the data collection and calculation can be carried out for all indicators that derive from the BCE study. However, this requires significant knowledge, skills and resources, which the NRAs currently do not always have inappropriate measure internally.

The alignment with the $5 \mathrm{G}$ readiness indicator should not cause significant difficulties for NRAs. As a new indicator, all NRAs should 
ideally apply the Communications Committee (COCOM) and European $5 \mathrm{G}$ Observatory methodology and include all three spectrum bands in their future activities.

Lastly, significant challenges and gaps remain for the Broadband price index. Although Albania, Kosovo*, North Macedonia and Serbia collected data and made the calculations, substantial challenges with respect to methodological alignments are identified. Due to its specific methodology, the Study on Mobile and Fixed Broadband Prices in Europe provides data collection in a very specific and very limited timeframe. The major challenge to ensure full alignment for the four economies lies in the time gap between the publication of the study methodology and the time needed for internal preparations and data collection. Moreover, frequent changes in the methodology provide additional challenges for all NRAs. Even the most experienced institutions in the WB region, such as RATEL (Serbia) and AEC and BCO (North Macedonia), reported that the latest methodological changes made the individual (for each economy) calculation practically impossible due to the delayed availability of the methodology, its complexity and the constant changes made.

\subsection{Human Capital Dimension}

Data collection for the Human capital dimension is the responsibility of the NSIs in all WB economies. Data for this dimension are extracted from three main statistical operations:

- ICT usage in households and by individuals survey (3 indicators)

- Labour Force Survey (LFS) (2 indicators)

- UNESCO OECD Eurostat (UOE) joint data collection on Education (1 indicator)

As for the ICT usage in households and by individuals survey, all NSIs achieved a high level of compliance with the ICT usage in enterprises survey Methodological Manuals and MQs provided by Eurostat and are adjusted every year. Data for each WB economy for all DESI indicators are available on Eurostat and can be used in the context of calculation of the DESI. Only minor methodological misalignments are detected for Montenegro as two indicators are flagged by Eurostat as low reliability.

Regarding the LFS, only Montenegro, North Macedonia and Serbia achieved a significant level of compliance with the EU-LFS. The NSIs of the three economies are already transmitting their data to Eurostat. In contrast, Albania, Bosnia and Herzegovina and Kosovo* are not fully aligned with the EU-LFS methodology, and thus do not transmit their data to Eurostat. To fill the gap, Bosnia and Herzegovina collect data for the two indicators by their inclusion in the ICT usage in enterprises survey using the same ISCO-08 classification as used in EU-LFS. Data for the two indicators are also available in the KAS database for Kosovo* but not transmitted to Eurostat. Also, Albania collects data for these indicators but from administrative sources. In order to increase the availability and quality of data, Albania, Bosnia and Herzegovina and Kosovo* should speed up the process for alignment with EU-LFS.

Lastly, Albania, Kosovo*, Montenegro, North Macedonia, and Serbia are able to provide data for the ICT graduates indicator that derives from the UNESCO OECD Eurostat (UOE) joint data collection on education. Out of the five economies, data for Montenegro, North Macedonia and Serbia are available on Eurostat. However, as flagged by Eurostat [63], some methodological misalignments exist as the definition differs for the three economies. In order to resolve this issue, NSIs of the three economies should align their definitions with the UOE methodology. Also, NSI from Albania and Kosovo* needs to start with the data transmission to Eurostat.

As for Bosnia and Herzegovina, data for the ICT graduates is not available in the BHAS database, but it is available in the entities statistical institutes (Institute for Statistics of Federation of $\mathrm{BiH}$ (FIS), and the Institute for Statistics of Republika Srpska (RSIS)). To resolve this issue, BHAS should align its domestic methodology on education with the UOE methodology and start with data transmission to Eurostat.

\subsection{Use of Internet Services Dimension}

Data collection for all eleven indicators in the Use of internet service dimension is the responsibility of the NSIs in all WB economies. Data for this dimension is extracted from the ICT usage in households and by individuals survey. Data for these indicators are already available on Eurostat and can be used for the calculation of DESI for all WB economies. The analysis showed that the high level of readiness is a result of the high level of compliance with the ICT usage in households and by individuals, Methodological Manuals and MQs provided by Eurostat achieved by the WB NSIs. However, to maintain a high level of compliance with Eurostat methodologies, all NSIs should make all the necessary annual adjustments as provided by Eurostat.

\subsection{Integration of Digital Technology Dimension}

Data collection for all seven indicators in the Integration of the digital technology dimension is the responsibility of the NSIs in all WB economies. Data for this dimension are extracted from the ICT usage in enterprises survey. Data for Bosnia and Herzegovina, Montenegro, North Macedonia, and Serbia are already transmitted and available on Eurostat, while Albania and Kosovo* are not transmitting these data yet.

The analysis revealed that all WB NSIs achieved a high level of compliance with the ICT usage in enterprises survey Methodological Manuals and MQs provided by Eurostat and are adjusted every year. However, some quality challenges remain as some of these data are flagged by Eurostat as low reliability, or not published by NSIs due to quality issues. Also, data for some indicators are not available since they were included in the latest survey or will be included in the 2021 survey.

To achieve full compliance and provide data for all DESI indicators, all WB NSIs should continue with their alignment and compliance with Eurostat methodologies and make all the necessary annual adjustments as provided by Eurostat. NSIs will also need to detect and resolve all quality issues detected by Eurostat. Also, NSIs of Albania and Kosovo* should take all necessary efforts to start transmission of the ICT usage in enterprises survey data to Eurostat.

\subsection{Digital Public Services Dimension}

As the case for the Connectivity dimension, data collection for the Digital public service dimension is divided among the NSIs (one 
indicator) and the ministries or agencies for the information society and digitisation (four indicators). ${ }^{4}$

The analysis found that the WB NSIs are responsible for data collection for one indicator (5a), which derives from the ICT usage in households and by individuals survey. All NSIs have achieved high compliance, and data for this indicator is available for all WB economies in the Eurostat database.

By contrast, significant challenges and gaps were detected for the remaining four indicators, which all fall under the jurisdiction of the ministries or agencies for the information society and digitisation. The main reason identified is that data for these indicators derives from the Commission ad hoc studies, such as eGovernment Benchmark Report (biannual) and Open Data Maturity Report (annual).

With respect to the eGovernment Benchmark Report, the latest 2020 edition included only Albania, Montenegro, North Macedonia, and Serbia, and constitutes a reliable score for three DESI indicators (5a2, $5 \mathrm{a} 3$ and 5a4). Data for Bosnia and Herzegovina and Kosovo* were not collected for the eGovernment Benchmark Report, and the Study found their domestic institutions have limited capacities for conducting similar studies domestically.

For Open Data, it is worth noting that data for all WB economies may be sources from global indexes measuring the Open data maturity (e.g. Open Data Index, Global Open Data Index, Open Data and Resilience Index). However, the score of these indexes cannot be used in the context of DESI as their methodologies are not aligned with the Commissions Open Data Maturity Report. As none of the WB economies was included in the latest 2020 Open Data Maturity Report, data is not available in the context of DESI for all WB economies. A positive example is a proactive approach taken by the Serbian NRA (RATEL), which uses the same methodology to calculate the score for Serbia.

\section{CONCLUSION}

This research found that all $\mathrm{WB}$ economies, and the responsible authorities, are aware of the importance of the data collection and the measurement of the progress in the context of the DESI. With respect to the first research question, i.e. how prepared are the $W B$ economies to provide full datasets for each DESI indicator, the analysis finds that the WB economies can provide data for calculation for $80 \%$ of the DESI 2020 indicators. In relation to the second research question, i.e. how are these data methodologically aligned with the DESI and other relevant methodologies, the analysis finds that for $8 \%$ of the DESI indicators, further methodological alignment is required. Data for $12 \%$ of the indicators for 2020 and earlier are not available. Common problems and challenges in the six WB economies are the indicators that derive from the Commission $\mathrm{ad}$ hoc studies, such as:

- Study on Broadband Coverage in Europe

- Study on Mobile and Fixed Broadband Prices in Europe

- eGovernment Benchmark

- Open Data Maturity Study

\footnotetext{
${ }^{4}$ Ministries or agencies for the information society and digitisation: NAIS - National Agency for the Information Society; Ministry of Transport and Communications (BA); Ministry of Public Administration, Digital Society and Media (ME); Agency for Information Society (XK); Ministry of Information Society and Administration (MK); and, Office for IT and eGovernment (RS).
}

In order to produce high-quality assessments and data in the context of DESI, all six WB economies need to be included in the Commission ad hoc studies or to be carried out special regional studies financially and technically supported by the Commission. In both scenarios, the WB authorities should actively participate in these studies to improve their competencies in the medium to long term.

To explore the findings of this paper further, we proposed to explore the readiness of other regions in Europe, especially the Eastern Partnership (EaP) countries (Armenia, Azerbaijan, Belarus, Georgia, Moldova and Ukraine) or outside of Europe. Also, the application of DESI, or an adapted version of i-DESI, in other nonEuropean countries and regions can be proven beneficial in terms of measuring the progress made in the digital economy and society.

\section{ACKNOWLEDGMENTS}

This paper is a result of the project "SmartEGOV: Harnessing EGOV for Smart Governance (Foundations, methods, Tools)/NORTE-010145-FEDER-000037", supported by Norte Portugal Regional Operational Programme (NORTE 2020), under the PORTUGAL 2020 Partnership Agreement, through the European Regional Development Fund (EFDR). It was also supported in part by the EC and the Regional Cooperation Council (Ref no. 095-020).

\section{REFERENCES}

[1] European Union, "Bangemann report: Europe and the global information society," 1994.

[2] J. Berleur and J.-M. Galand, "ICT Policies of the European Union: From an Information Society to eEurope. Trends and visions," in Perspectives and Policies on ICT in Society: An IFIP TC9 (Computers and Society) Handbook, J. Berleur and C. Avgerou, Eds. Boston, MA: Springer US, 2005, pp. 37-66.

[3] European Union, "Europe 2020: A Strategy for Smart, Sustainable and Inclusive Growth." 2010.

[4] European Commission, "A Europe fit for the digital age (Priorities 2019-2024)," 2019. https://ec.europa.eu/info/strategy/priorities-2019-2024/europe-fit-digitalage en (accessed Apr. 15, 2021).

[5] European Union, "Key Indicators," 2021. https://digital-agenda-data.eu/datasets/ digital_agenda_scoreboard_key_indicators/indicators\#security-and-privacy (accessed Apr. 15, 2021).

[6] European Commission, "The Digital Economy and Society Index (DESI)," 2021. https://ec.europa.eu/digital-single-market/en/digital-economy-and-societyindex-desi.

[7] A. Stavytskyy, G. Kharlamova, and E. A. Stoica, "The Analysis of the Digital Economy and Society Index in the EU," Balt. F. Eur. Stud., vol. 9, no. 3, pp. 245-261, Sep. 2019, doi: 10.1515/bjes-2019-0032.

[8] M. Moroz, "The Level of Development of the Digital Economy in Poland and Selected European Countries: A Comparative Analysis," Found. Manag., vol. 9, no. 1, pp. 175-190, Feb. 2017, doi: 10.1515/fman-2017-0014

[9] European Commission, "Digital Economy and Society Index (DESI) 2020 - Methodological note," 2020. [Online]. Available: http://ec.europa.eu/newsroom/dae/ document.cfm?doc id=67082.

[10] Z. Bánhidi, I. Dobos, and A. Nemeslaki, "What the overall Digital Economy and Society Index reveals: A statistical analysis of the DESI EU28 dimensions," Reg. Stat., vol. 10, no. 2, pp. 46-62, 2020, doi: 10.15196/RS100209.

[11] EU-Western Balkans Summit Declaration. 2003.

[12] Parliament of the Republic of Montenegro, Declaration of Independence Republic of Montenegro. Montenegro, 2006.

[13] Assembly of Kosovo, Kosovo Declaration of Independence. Kosovo, 2008.

[14] European Commission, "Candidate Countries and Potential Candidates," 2021. https://ec.europa.eu/environment/enlarg/candidates.htm.

[15] M. Meyerhoff Nielsen and Z. Jordanoski, "Digital transformation, governance and coordination models: A comparative study of Australia, Denmark and the Republic of Korea," 2020, doi: 10.1145/3396956.3396987.

[16] M. Meyerhoff Nielsen and J. Millard, "Local Context, Global Benchmarks: Recommendations for an Adapted Approach Using the UN E-Government Development Index as an Example," in The 21st Annual International Conference on Digital Government Research, 2020, pp. 253-260, doi: 10.1145/3396956.3396969. 
[17] M. I. Manda and J. Backhouse, Digital transformation for inclusive growth in South Africa: challenges and opportunities in the 4 th industrial revolution. 2017

[18] E. Ossiannilsson and N. Ioannides, "Towards a Framework and Learning Methodology for Innovative Mobile Learning: A Theoretical Approach," 2017, doi: $10.1145 / 3136907.3136929$.

[19] M. Meyerhoff Nielsen, "The Role of Governance, Cooperation, and eService Use in Current eGovernment Stage Models," 2016

[20] M. Meyerhoff Nielsen, "The Demise of eGovernment Maturity Models: Framework and Case Studies," Tallinn University of Technology Press, Tallinn, 2020.

[21] R. Heeks and S. Bailur, "Analyzing e-government research: Perspectives, philosophies, theories, methods, and practice," Gov. Inf. Q., vol. 24, no. 2, pp. 243-265, Apr. 2007, doi: 10.1016/j.giq.2006.06.005

[22] UNDESA, "E-Government Survey 2014: E-Government for the future we want," New York, 2014.

[23] N. Negroponte, Being Digital. New York: Hodder and Stoughton, 1995.

[24] J. P. Bowman, "The Digital Economy: Promise and Peril in the Age of Networked Intelligence," Acad. Manag. Perspect., vol. 10, no. 2, pp. 69-71, May 1996, doi 10.5465/ame.1996.19198671.

[25] T. Mesenbourg L., "Measuring the Digital Economy," 2001. [Online] Available: https://www.census.gov/content/dam/Census/library/workingpapers/2001/econ/umdigital.pdf.

[26] M. Raisinghani, Business Intelligence in the Digital Economy: Opportunities, Limitations and Risks. USA: IGI Global, 2004.

[27] M. Ribble and A. Shaaban, Digital Citizenship in Schools Second Edition. 2011.

[28] A. Lemaire, Forging a Digital Society. OECD Publishing, 2016.

[29] S. Serpa and C. M. Ferreira, "Sustainability and Digital as Challenges of Sociology," f. Educ. Soc. Res., vol. 10, no. 2, p. 15, Mar. 2020, doi: 10.36941/jesr-2020-0023.

[30] C. M. Ferreira and S. Serpa, "Society 5.0 and Social Development: Contributions to a Discussion," Manag. Organ. Stud., vol. 5, no. 4, p. 26, Nov. 2018, doi 10.5430/mos.v5n4p26.

[31] J. Haltiwanger and R. Jarmin, "Measuring the Digital Economy," Jun. 1999.

[32] P.-M. Boulanger, "Sustainable development indicators: A scientific challenge, a democratic issue," Sapiens, vol. 1, Jun. 2008, doi: 10.5194/sapiens-1-59-2008.

[33] DFS - Digital Future Society, "Measuring the margins: A global framework for digital inclusion," Barcelona, 2019.

[34] R. Heeks, "Understanding and measuring eGovernment: international benchmarking studies," UNDESA Work. E-Government Underst. Present Creat. Futur. Budapest, Hungary, pp. 27-28, 2006.

[35] A. Huovila, P. Bosch, and M. Airaksinen, "Comparative analysis of standardized indicators for Smart sustainable cities: What indicators and standards to use and when?” Cities, vol. 89, pp. 141-153, 2019.

[36] K. Kononova, "Some Aspects of ICT Measurement: Comparative Analysis of E-Indexes,” Proc. 7th Int. Conf. Inf. Commun. Technol. Agric. Food Environ., Jan. 2015

[37] World Economic Forum, "Networked Readiness Index 2016," 2016

[38] World Economic Forum, "The Global Competitiveness Report 2018." [Online]. Available: http://www3.weforum.org/docs/GCR2018/05FullReport/ TheGlobalCompetitivenessReport2018.pdf.

[39] Economist Intelligence Unit, "The Inclusive Internet Index," 2020. https:// theinclusiveinternet.eiu.com/.

[40] International Telecommunication Unit, "ICT Development Index," 2020. https: //www.itu.int/en/ITU-D/Statistics/Pages/facts/default.aspx.

[41] United Nations E-Government Knowledge Base, "E-Government Development Index," 2020. https://publicadministration.un.org/egovkb/en-us/ About/Overview/E-Government-Development-Index.

[42] Waseda Univeristy, "Digital Governance Ranking." https://idg-waseda.jp/ranking htm.

[43] Alliance for Affordable Internet, "The 2019 Affordability Report," Washington DC.

[44] E. A. Stoica and I. A. Bogoslov, "A Comprehensive Analysis Regarding DESI Country Progress for Romania Relative to the European Average Trend," Balk Reg. Conf. Eng. Bus. Educ., vol. 2, no. 1, pp. 258-266, Dec. 2017, doi: 10.1515/cplbu2017-0034.

[45] G. Skintzi and A. Kontolaimou, "Digitisation patterns of the Greek economy and society," Nov. 2018.

[46] A. Scupola, "Digital Transformation of PublicAdministration Services in Denmark:A Process Tracing Case Study," Nord. Balt. J. Inf. Commun. Technol., vol. 2018, pp. 261-284, Jan. 2019, doi: 10.13052/nbjict1902-097X.2018.014.

[47] N. Urs, "E-government development in Romanian local municipalities: A complicated story of success and hardships "," Transylvanian Rev. Adm. Sci., vol. 55, no. E, pp. 118-129, Oct. 2018, doi: 10.24193/tras.55E.8

[48] V. Russo, "Digital Economy and Society Index (DESI). European Guidelines and Empirical Applications on the Territory BT - Qualitative and Quantitative Models in Socio-Economic Systems and Social Work," J. L. Sarasola Sánchez-Serrano, F. Maturo, and Š. Hošková-Mayerová, Eds. Cham: Springer International Publishing
2020, pp. 427-442.

[49] E. Mirke, E. Kasparova, and S. Cakula, Adults' readiness for online learning in the Czech Republic and Latvia (digital competence as a result of ICT education policy and information society development strategy). 2019.

[50] M. Nikolov, Hari Stankov; Krumova, "Hofstede's Model in the Context of EGovernment and Open Government in EU Countries: Countries Clustering Based on Similarities and Differences," Smart Cities Reg. Dev. Journal, Universul Acad. Publ. House, vol. 3, no. 1, pp. 29-46, 2019.

[51] M. Götz, "Industry 4.0 - the perspective of international economics. The case of Polish-German Relationships," Przeglad Zach., vol. 4, pp. 169-185, 2014.

[52] A. Moreno Llamas, J. García-Mayor, and E. Cruz-Sánchez, "The impact of digital technology development on sitting time across Europe," Technol. Soc., vol. 63, p. 101406, Nov. 2020, doi: 10.1016/j.techsoc.2020.101406.

[53] M. A. P. Alonso and J. C. S. García, "Digitalization as Push and Pull Factor Redefining the Entrepreneurship Concept," no. 2017-09, K. Todorov and K. Kolarov, Eds. Bulgarian Association for Management Development and Entrepreneurship, 2018, pp. 175-191 BT-The International Entrepreneurship:

[54] K. Curko, T. Curic, and V. B. Vukšic, "Perspective of smart business development," Int. 7. Renew. Energy Sources, vol. 2, 2017.

[55] UNDESA - United Nations Department of Economic and Social Affairs, "EGovernment Readiness Survey Database," 2018.

[56] European Commission, "Monitoring the digital economy and electronic communications services in the Western Balkans and Turkey," 2018. doi: 10.2759/809948.

[57] European Commission, "Monitoring the digital economy and electronic communications services in the Western Balkans and Turkey," 2019. doi: 10.2759/134022.

[58] European Commission, "Monitoring the digital economy and electronic communications services in the Western Balkans and Turkey," 2020. doi: 10.2759/97278.

[59] P. Baxter and S. Jack, "Qualitative Case Study Methodology: Study Design and Implementation for Novice Researchers,” Qual. Rep., Jan. 2015, doi: 10.46743/21603715/2008.1573.

[60] R. K. Yin, Case study research: design and methods. Thousand Oaks, Calif.: Sage Publications, 2003

[61] I. Rohlfing, Case Studies and Causal Inference: An Integrative Framework. Basingstoke, UK: Palgrave Macmillan, 2012.

[62] M. Patton, "Qualitative Research And Evaluation Methods," http://lst-iiep.iiepunesco.org/cgi-bin/wwwi32.exe/[in=epidoc1.in]/?t2000=018602/(100), vol. 3, Jan. 2002.

[63] Eurostat, "Digital Economy and Society Database," 2021. https://ec.europa. eu/eurostat/web/digital-economy-and-society/data/database (accessed Apr. 15, 2021).

[64] State Statistical Office (North Macedonia) "Statistical Database" 2021. http://makstat.stat.gov.mk/PXWeb/pxweb/mk/MakStat/MakStat_ _InfOpstestvo__DomakinstvaPoedinci.

[65] Statistical Office of the Republic of Serbia, "Statistical Database," 2021. https: //data.stat.gov.rs/?caller=SDDB (accessed Apr. 15, 2021)

[66] Institute of Statistics (Albania), "Statistical Database," 2021. http://databaza.instat. gov.al/pxweb/sq/DST/?rxid=de9c2266-23e7-4e41-a02e-91c210b1c568 (accessed Apr. 15, 2021).

[67] Statistical Office of Montenegro, "Statistical Database," 2021. http://195.66.179. 231/PXWeb/pxweb/sr/?rxid=02bd2fd2-80bd-4f21-851b-ac900fb860ca (accessed Apr. 15, 2021).

[68] Kosovo Agency of Statistics, "Statistical Database," 2021. https://askdata.rksgov.net/PXWeb/pxweb/en/askdata/ (accessed Apr. 15, 2021).

[69] Agency for Statistics of Bosnia and Herzegovina, "Statistical Database," 2021. http://www.bhas.ba/Calendar/Category/29 (accessed Apr. 15, 2021)

[70] Republic Agency for Electronic Communications and Postal Service (Serbia), "Reports," 2021. https://www.ratel.rs/cyr/page/cyr-kvartalni-podaci-elektronskekomunikacije (accessed Apr. 15, 2021).

[71] Broadband Competence Office (North Macedonia), "Reports," 2021. https://bco. mioa.gov.mk/?page_id=228\&lang=en (accessed Apr. 15, 2021).

[72] Agency for Electronic Communications (North Macedonia), "Reports," 2021. https://aek.mk/ податоци-за-пазар/ (accessed Apr. 15, 2021).

[73] Communications Regulatory Agency (Bosnia and Herzegovina), "Reports," 2021. https://www.rak.ba/bs-Latn-BA/telecom-market-analysis (accessed Apr. 15, 2021).

[74] Agency for Electronic Communications and Post (Albania), "Reports," 2021. https: //www.akep.al/home-perdorues/\#1533244041316-4-2 (accessed Apr. 15, 2021).

[75] Regulatory Authority of Electronic and Postal Communications (Kosovo), "Reports," 2021. http://www.arkep-rks.org/?cid=1,32 (accessed Apr. 15, 2021).

[76] U. Reja, K. Manfreda, V. Hlebec, and V. Vehovar, "Open-ended vs. Close-ended Questions in Web Questionnaires," Adv Methodol Stats, vol. 19, Jan. 2003

[77] M. P. COUPER, M. W. TRAUGOTT, and M. J. LAMIAS, "Web Survey Design and Administration", Public Opin. Q., vol. 65, no. 2, pp. 230-253, Jun. 2001, doi: $10.1086 / 322199$

[78] M. L. Upcraft and J. Schuh, "Assessment in Student Affairs: A Guide for Practitioners. The Jossey-Bass Higher and Adult Education Series.," 1996 